\title{
Costeos Variable y por Absorción Aplicados a la Realidad Peruana
}

\author{
CPC Bernardo Sanchez Barraza
}

Docente auxiliar

\begin{abstract}
RESUMEN
Cuando una empresa peruana necesita saber si el negocio que realiza es rentable emplea el estado de resultados de un período específico para así lograr medir la ganancia obtenida. Este estado financiero puede ser preparado mediante dos métodos de costeo de inventario, absorbente y variable, es por ello que a continuación revisaremos los conceptos en los que se basan, pero desde una perspectiva comparativa y analítica, sin olvidar su relación con la normatividad contable y tributaria, finalizando con las conclusiones y recomendaciones enmarcadas en nuestra realidad.
\end{abstract}

Palabras clave: Materia prima, mano de obra, gastos operativos, costo de fabricación, costos fijos, inventarios, ventas, tributación.

\section{INTRODUCCIÓN}

El continuo batallar de las empresas peruanas para ser rentables y competitivas es una preocupación constante y creciente en la actualidad. Ellas hacen uso de todos los conocimientos que la contabilidad, administración y economía le puedan brindar. Por consiguiente, se hace imperiosa la necesidad de contar con información confiable y veraz en todo momento, que permita la adecuada toma de decisiones a nivel interno y externo. En este contexto, las empresas deben revalorar dos métodos proporcionados por la contabilidad de costos, nos referimos al Costeo Variable y al Costeo por Absorción, los cuales, hoy en día, no son utilizados adecuadamente según las necesidades de las empresas, más aún, existen una serie de dificultades en su aplicación y comprensión que limitan el actuar o que conducen a una inadecuada toma de decisiones, por ello a continuación revisaremos las bases teórico-prácticas que los sostienen desde una perspectiva de la realidad peruana.

\section{COSTEO VARIABLE Y COSTEO POR ABSORCION}

\section{Costeo Variable (Directo)}

Considera como costos de producción de un producto sólo a los costos variables, es decir, materia prima directa, mano de obra directa y costos indirectos de fabricación variables. Los costos indirectos de fabricación fijos y los gastos operativos de administración y ventas (variables y fijos) deben llevarse al período enfrentándolos a los ingresos generados en él. Los defensores de este método sostienen que los costos fijos de fabricación corresponden a la capacidad instalada de planta, dentro de un rango relevante, pero como son fijos no se alteran por el volumen de producción, como si lo hacen los costos variables.

\section{Costeo por Absorción (Total)}

Incluye en el costo de un producto el total de todos los costos de fabricación inde- 
pendientemente de si son variables o fijos. $\mathrm{El}$ sustento de este método es que para poder fabricar un producto se necesitan de estos dos tipos de costos. En cuanto a los gastos administrativos y de ventas (variables y fijos) se llevan a resultados en el período correspondiente.

\section{COMPARACIÓN DE LOS MÉTODOS DE COSTEO}

La principal diferencia entre los métodos de costeo radica en que el costeo variable no asigna los costos fijos de producción a los inventarios de los productos, en cambio el costeo absorbente si lo hace; por lo tanto, estos costos si son inventariables dentro del costo del producto y en la determinación del costo unitario de fabricación. Por otro lado, la forma de presentar la información en el estado de resultados es diferente en ambos métodos. En el Costeo Variable se resta a los ingresos los costos y gastos variables de las unidades vendidas, obteniendo el margen de contribución, a éste se le deducirán los costos y gastos fijos totales dando por resultado el ingreso operacional. En contraste, el Costeo por Absorción deduce a los ingresos el costo de producción (variable y fijo) de los productos vendidos, determinándose la utilidad bruta; por último, a dicha utilidad se le extraerán los gastos de administración y de ventas (variables y fijos) y el resultado obtenido será el ingreso operacional. Por lo tanto, el costeo variable emplea un formato de "contribución marginal" y el absorbente uno de "margen bruto".

Otro aspecto importante del contraste de métodos es que las utilidades pueden ser cambiadas con incrementos o reducciones de los inventarios y según el método que se use. Por ejemplo, la utilidad será mayor en el costeo variable si las unidades vendidas son mayores que las unidades producidas, esto se debe a que tendré más ingresos para cubrir una cantidad constante de costos fijos, en cambio en el costeo absorbente la utilidad será menor porque al vender más cantidad de la que se ha producido también estoy enfrentando costos fijos inventariados de periodos pasados, provenientes de las unidades del inventario y que estoy vendiendo, contra ingresos presentes. Para que suceda lo contrario se debe vender menos unidades que las que se produjeron para así guardar en inventarios costos fijos y no mermar los ingresos presentes, en el costeo variable se tendrá menos ingresos para cubrir la misma cantidad de costos fijos. Si las ventas y la producción son iguales y no se tiene inventarios finales ambos métodos obtendrán el mismo nivel de utilidades.

\section{AJUSTE POR CAPACIDAD: ¿Sólo en el costeo por absorción?}

Cuando una empresa tiene una capacidad de planta establecida, puede fabricar un número máximo de productos y para ello emplea un monto de costos fijos constante, se alcance o no ese nivel productivo. Surge entonces la interrogante: ¿Qué sucede con el costo fijo unitario cuando se produce menos unidades que la capacidad de planta? La respuesta es: Simplemente fluctúa, si se produce más disminuye, si se produce menos aumenta. Esta distorsión debe corregirse en el costeo absorbente, toda vez que al tener menos unidades producidas que la capacidad de planta, faltarán unidades que soporten los costos fijos unitarios. La corrección se efectúa mediante un ajuste, que halla la diferencia de unidades de la capacidad de planta y de la producción real alcanzada y la multiplica por el costo fijo unitario (costos fijos totales/capacidad de planta en unidades), el resultado monetario obtenido deberá ser restado en el estado de resultados cuando no se haya alcanzado la capacidad de planta y su- 
marlo cuando se sobrepase dicha capacidad. En el costeo variable este ajuste jamás puede darse porque todos los costos fijos son enfrentados al periodo, entonces así no se cubra la capacidad de producción de planta de todas formas se incurrirá en los costos fijos.

En el Perú esta práctica de ajuste es pocas veces realizada, a pesar que nuestra industria en general, no alcanza a producir ni la mitad de la capacidad de planta existente. Lo que se opta por hacer en las empresas es determinar el costo de ventas por diferencias de fórmulas y como en ellas se contiene el costo fijo total se estaría ajustando indirectamente, pero a un costo unitario de producción distorsionado; otro inconveniente es que no permite el análisis período a período de cuanto porcentaje de las instalaciones en planta están siendo realmente empleadas en la fabricación y así decidir si se reduce la capacidad de planta o se deja para que los cambios de demanda estacionales compensen esa capacidad ociosa inevitable pero necesaria para producir.

\section{ASPECTOS CONTABLES Y TRIBUTARIOS}

La NIC 2 nos orienta a costear los productos por el método absorbente o total. Esta norma al no mencionar el costeo variable nos hace deducir que dicho costeo no contempla necesariamente las normas contables para su realización y que su utilización será en informes internos, además por su comportamiento de variabilidad del costo es conveniente usarlo para planeación control y toma de decisiones internas. El costeo absorbente debe ser usado en informes externos que se presentan ante instituciones financieras, administraciones tributarias y entes reguladores, como sustento de ello debemos recordar que la Ley del Impuesto a la Renta en Perú pone énfasis en la preferencia de usar el costeo absorbente o total para el costeo de inventarios y, como todos sabemos, esta norma es de carácter tributario. Mas aún, para el cálculo definitivo de los impuestos la utilidad contable obtenida mediante el costeo absorbente deberá ser conciliada con los agregados y deducciones exigidos por ley para la obtención de la utilidad tributaria, la cual es objeto del cálculo del impuesto a la renta.

Cabe mencionar que los inventarios contenidos en el Balance General diferirán en valor según el método de costeo empleado, siendo mayores mediante el costeo absorbente, debido a la inclusión de los costos fijos de fábrica; este hecho también afecta a los Estados de Costo de producción, Estado de Costo de Ventas y Estado de Resultados.

\section{CONCLUSIONES}

El método de costeo absorbente debe ser usado para fines externos y el costeo variable para fines internos, por lo tanto esta diferenciación se puede resumir en una frase: "costos diferentes para fines diferentes", aunque se parte de un mismo conglomerado de costos, el profesional es capaz de adecuar la información a sus necesidades.

Los costos fijos al ser inventariados en los productos mediante el costeo absorbente generan una diferencia de utilidades en contraste con el costeo variable.

Las empresas peruanas no aplican correctamente la metodología del costeo absorbente.

\section{RECOMENDACIÓN}

Difundir los conceptos de costeo absorbente y costeo variable entre las empresas peruanas y concientizar sobre la importancia del ajuste de capacidad de planta en nuestro 
país, en el cual el sector industrial y su capacidad de planta total se encuentran en un estado recesivo por falta de demanda de productos. Para lograr esto las universidades, colegios profesionales y contadores en general debemos de comprometernos en dicha labor de difusión.

\section{REFERENCIAS}

1 Horngren, Charles. Contabilidad de costos. Un enfoque gerencial. 10. ${ }^{2}$ ed., México. Prentice-Hall. Hispanoamericana S.A. Pearson. 2002.
2 Gayle Rayburn, Leticia. Contabilidad y administración de costos. 6. ${ }^{2}$ ed., México. Mc Graw-Hill. Interamericana Editores. S. A. 1999.

3 Polimeni, Ralph. Contabilidad de Costos. 3. ${ }^{a}$ ed., Colombia. Mc Graw-Hill. Interamericana S.A., 2000.

4 Estudio Caballero Bustamente. Manual Tributario 2004. Lima. Estudio Caballero Bustamante. 2004.

5 Vargas C., Víctor. Separata del Curso Integral de Normas Internacionales de Contabilidad. Lima. Investigación y Desarrollo Empresarial. 2004 